\title{
Proprioceptive elbow training reduces pain and improves function in painful lateral epicondylitis - a prospective trial
}

\author{
B. Schiffke-Juhász ${ }^{1 *}$, K. Knobloch², P. M. Vogt ${ }^{3}$ and L. Hoy ${ }^{4}$
}

\begin{abstract}
Background: In painful epicondylitis, previous studies reported deficiencies in elbow proprioception. In line, proprioceptive training of the lower limb has been reported substantial beneficial in a number of indications. Therefore, we have asked if a specified proprioceptive training using training devices that are capable of activating the deep musculature in the upper limb is able to reduce the symptoms of epicondylitis.

Materials and methods: We included 71 patients with painful lateral epicondylitis > 3 months. Interventions: Group A: Proprioceptive training intervention with a Flexibar ${ }^{\circledR}(9$ min daily for 12 weeks). Group B: at least 40 min running or walking/week with the $\mathrm{XCO}^{\circledast}$ in addition to the proprioceptive training with the Flexibar ${ }^{\circledast}(9$ min daily for 12 weeks), follow-up for 12 weeks. Primary end point: Pain on visual analogue scale (VAS, 0-10); secondary end points: DASH-Score $(0=$ very good, $100=$ very poor $)$, grip strength according to Jamar dynamometer $(\mathrm{kg})$, vibration sensation measured with a $128 \mathrm{~Hz}$ tuning fork.

Results: The pain on VAS in group A was reduced significantly. $3.6 \pm 2.0$ to $2.4 \pm 2.1(-33 \%, p=0.013)$, and from $3.7 \pm 2.4$ to $2.2 \pm 1.9(-41 \%, p=0.004)$ in group B after 12 weeks. There was no significant difference between A and $B(p=0.899)$. In both groups, there was a significant improvement of the DASH-Score (A: $32 \pm 15$ to $14 \pm 12$, $-56 \%, p<0.001 ; B: 27 \pm 12$ to $12 \pm 11,-55 \%, p=0.001)$ without any difference between groups $A$ and $B(p=$ 0.339). Grip strength improvement in group A from $24 \pm 12$ to $33 \pm 11 \mathrm{~kg}(+38 \%, p<0.001)$, and from $29 \pm 14$ to $34 \pm 11 \mathrm{~kg}(+15 \%, p<0.001)$ in group B. In line, vibration sensation improved in both groups (A: $6.3 \pm 0.6$ to $6.5 \pm$ $0.5, p=0.0001 ; \mathrm{B}: 6.3 \pm 0.7$ to $6.6 \pm 0.5, p=0.003)$.
\end{abstract}

Conclusion: A 12-week proprioceptive training with the Flexibar ${ }^{\circledast}$ improves pain, quality of life, grip strength and vibration sensation in patients with painful lateral epicondylitis.

Level of evidence: $\mathrm{lb}$, randomised clinical trial

Trial registration: German Clinical Trials Register, DRKS00024857, registered on 25 March 2021—retrospectively registered, http://apps.who.int/trialsearch/

Keywords: Epicondylitis humeri radialis, Tennis elbow, Proprioception, Proprioceptive exercise

\footnotetext{
* Correspondence: berit.schiffke@gmx.de

${ }^{1}$ Herzogin Elisabeth Hospital, Braunschweig, Germany

Full list of author information is available at the end of the article
}

\section{$\triangle B M C$}

C C The Author(s). 2021 Open Access This article is licensed under a Creative Commons Attribution 4.0 International License, which permits use, sharing, adaptation, distribution and reproduction in any medium or format, as long as you give appropriate credit to the original author(s) and the source, provide a link to the Creative Commons licence, and indicate if changes were made. The images or other third party material in this article are included in the article's Creative Commons licence, unless indicated otherwise in a credit line to the material. If material is not included in the article's Creative Commons licence and your intended use is not permitted by statutory regulation or exceeds the permitted use, you will need to obtain permission directly from the copyright holder. To view a copy of this licence, visit http://creativecommons.org/licenses/by/4.0/. The Creative Commons Public Domain Dedication waiver (http://creativecommons.org/publicdomain/zero/1.0/) applies to the data made available in this article, unless otherwise stated in a credit line to the data. 


\section{Background}

The epicondylitis humeri radialis, often simply referred to as tennis elbow, appears with an incidence of $1-3 \%$ in the population $[1,2]$, and occurs most frequently between the third and fifth decade of life [1]. Amongst women between the 40th and 50th year of life the disease may occur with a prevalence of $10 \%$ [2]. Thereby, the epicondylitis humeri radialis is not only a very widespread disease but also affects more often the working population. Even though the aetiology of the disease has still not been fully identified and it seems to be determined multifactorially, a number of studies have shown that there are various risk factors, for example, repetitive movements, forceful work or activities which require an unnatural posture of hands and arms [3, 4]. Such stresses cannot only be found amongst active tennis players but also within a lot of professional activities, so that only a small part of the patients with lateral epicondylitis exercises the name-giving sport at all [1]. Another risk factor relating to a low social support at work could be identified amongst female patients [3]. Furthermore, there seems to be a relation with a current or previous nicotine abuse [3, 4]. In addition, further studies were able to demonstrate reduced deficiencies in proprioception in patients with symptomatic lateral epicondylitis [5].

Even though Cyriax already described, in 1936, a spontaneous consolidation of the symptoms after about 8-12 months on the condition of functional physical rest [1], most patients expect a quicker therapeutical intervention, so that the question concerning an appropriate therapy is further relevant. At this point, a very wide spectrum of therapeutical options is available for therapists, which were repetitively compared against each other within various studies. In this context, it could be shown that there is no universal solution for the therapy of the lateral epicondylitis, but that patients benefit from various therapeutic approaches. Whereas surgical treatment only play a role in cases of failure of the conservative therapeutic options $[1,6]$, there are, besides rarely applied conservative therapeutic options, often treatments using orthoses, injections and physiotherapy in the foreground. In case of a treatment using orthoses, it can be chosen from a lot of different types of orthoses, whereby a number of studies could not prove relevant differences in the outcome of the different types of orthoses [7], though Garg et al. could indeed find a slight advantage in the pain reduction of using wrist extension splints rather than using usual epicondylitis braces [8]. However, the pain relief is here tied to wearing the orthosis, whereby the affected muscles only get a relief but no sustainable functional optimisation. Another frequently used therapeutic option is a local injection, most common with a medical preparation of cortisone (rarer used are PRP, Botox, or others). In doing so, it is essential to take into account not only the therapeutic effect but also the risk potential due to systemic complications (for example multifocal osteonecrosis or other well-known systemic side effects) and the possibility of local complications (for example tendon or fascial ruptures) [9]. As demonstrated in various studies, the therapeutic effect of injection treatment seems to be only superior in the short-term follow-up to the physiotherapeutic options [10]. With regard to the use of PRP, Ang Li et al. found inferiority to corticosteroids after 4-8 weeks, but superiority of PRP in the long term (after 24 weeks) [11]. Ruiz et al. were also able to show improvements in symptoms for the use of botulinum toxin, but accompanied by a certain weakness of the 3rd finger, without other side effects [12]. Another study by Newcomer et al. ultimately identified rehabilitation as the first-line therapy for short-lasting symptoms [13]. However, it should be noted that the repertoire of physiotherapeutic options with over 40 different methods [6] is extremely wide spread, so that even at this point a calculated decision regarding a suitable therapeutic option becomes necessary. As deficiencies in proprioception can play a role in different tendon diseases which was explicitly proven by Juul-Kristensen et al. for patients with lateral epicondylitis compared to healthy control subjects [5], we aspired to design a training concept to improve the proprioceptive capabilities regarding the affected area. In this context, we have chosen to examine not only the training with one or two appropriate training devices to run a prospective, randomised clinical trial with regard to the improvement of the proprioceptive capabilities but also the clinical development of the symptoms.

\section{Hypothesis}

The combination of a proprioceptive and ballistic training is effective for patients with lateral epicondylitis regarding pain reduction and functional improvement.

\section{Materials and methods}

Agreement of the ethics committee: Medizinische Hochschule Hannover, Germany.

\section{Inclusion criteria}

Patients suffering epicondylitis humeri radialis for at least 3 months, verified by clinical examination with exercise related pain, at the age of 18 to 65 years. Therefore used diagnosis criteria were pain on palpation of 
the lateral epicondyle as well as the declaration of pain during provocation tests.

\section{Exclusion criteria}

Epicondylitis humeri ulnaris, missing consent, beginning of different therapeutic treatments during the study phase.

\section{Patient characteristics}

Figure 1 illustrates the course of the study in form of a CONSORT flow chart. This includes an evaluation of 108 patients to verify clinically the existence of a lateral epicondylitis by medical history as well as performing significant clinical tests (pain on palpation of the lateral epicondyle, painful extension of fingers against resistance). Seventy-one patients with lateral epicondylitis were subsequently randomised by lottery into two groups. The lottery has taken place by drawing an opaque lot with the designation 'Group A' or 'Group B'. The patients' characteristics of both groups are shown in an overview in Tables 1 and 2.

\section{Intervention}

The intervention in 'Group A' consisted in an at least 12-week training with the Flexibar'. The Flexibar ${ }^{\bullet}$ is a swing bar with rubber weights at the ends. The device is actively vibrated. The alternating vibration causes an additional reflexive tensioning of the deep muscles. We requested a daily training of at least $9 \mathrm{~min}$, whereby the exercises shown in Fig. 2 ought to be performed in each case for $30 \mathrm{~s}$ per limb.

Test subjects in 'Group B' were requested to do the same training programme, but received an additional other training device-the $\mathrm{XCO}^{\circ}$ Walking \& Running. The $\mathrm{XCO}^{\circ}$ Walking \& Running is a metal tube filled with a granulate (Fig. 3). The granulate is set in motion by the swing of the arm whilst walking and each time the granulate hits the ends of the tube, a socalled 'reactive impact' occurs, which in turn should lead to a reflexive, stabilising tensioning of the deep muscles. With that training device, the patients had to complete 2 further training sessions per week. Each training session should include at least $20 \mathrm{~min}$ of walking or running with the training device. Thereby, the $\mathrm{XCO}^{\circ}$-tubes should be held one in each

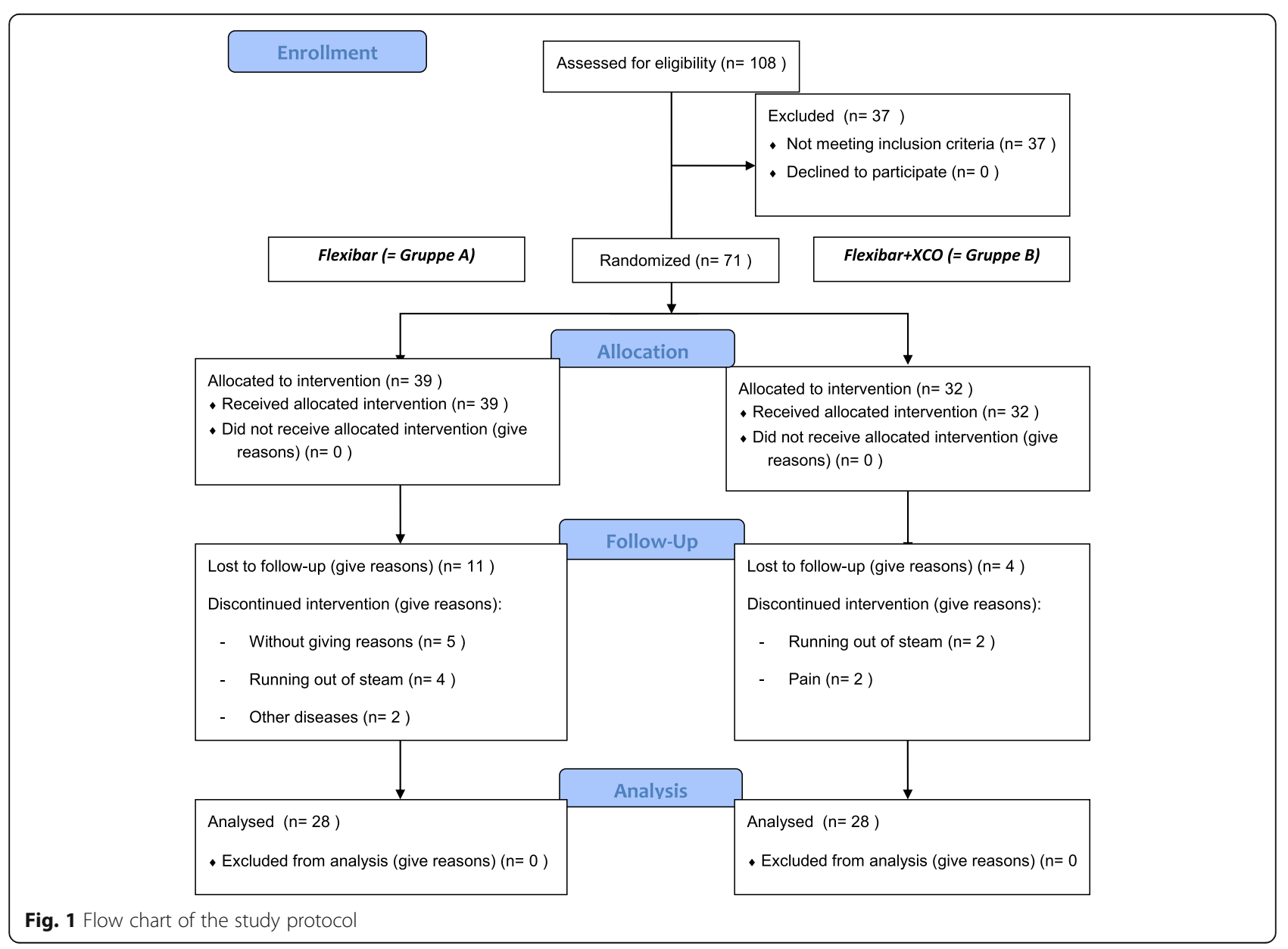


Table 1 General characteristics

\begin{tabular}{|c|c|c|c|}
\hline & Group A (Flexibar ${ }^{\oplus}$ ) & Group B (Flexibar ${ }^{\oplus}+\mathrm{XCO}^{\oplus}$ ) & Chi-square test \\
\hline \multicolumn{4}{|l|}{ Basic characteristics } \\
\hline Gender & $m=15 ; f=24$ & $m=17 ; f=15$ & 0.217 \\
\hline Age [years] & $47 \pm 8$ & $47 \pm 8$ & 0.173 \\
\hline Weight [kg] & $72 \pm 15$ & $76 \pm 12$ & 0.300 \\
\hline Height [cm] & $173 \pm 8$ & $175 \pm 10$ & 0.006 \\
\hline BMl & $24.2 \pm 4.3$ & $24.7 \pm 3.5$ & 0.352 \\
\hline \multicolumn{4}{|l|}{ Underlying diseases } \\
\hline Nicotine abuse & $15 \%$ & $13 \%$ & 0.728 \\
\hline Diabetes & $3 \%$ & $0 \%$ & 0.362 \\
\hline Hypercholesterolemia & $8 \%$ & $9 \%$ & 0.800 \\
\hline Hypertension & $8 \%$ & $13 \%$ & 0.499 \\
\hline Heart disease & $0 \%$ & $3 \%$ & 0.266 \\
\hline Intake of acetylsalicylic acid & $5 \%$ & $6 \%$ & 0.838 \\
\hline Intake of cortisone (spray) & $3 \%$ & $13 \%$ & 0.103 \\
\hline \multicolumn{4}{|l|}{ Diseases of the elbow } \\
\hline Family disposition & neg. $=29 ;$ pos. $=10$ & neg. $=27 ;$ pos. $=5$ & 0.341 \\
\hline Pain of right elbow & $74 \%$ & $69 \%$ & 0.539 \\
\hline Pain of left elbow & $5 \%$ & $13 \%$ & 0.539 \\
\hline Bilateral pain of elbow & $21 \%$ & $19 \%$ & 0.539 \\
\hline Morning stiffness & $33 \%$ & $28 \%$ & 0.585 \\
\hline Swelling & $15 \%$ & $13 \%$ & 0.695 \\
\hline Pressure pain & $90 \%$ & $88 \%$ & 0.522 \\
\hline Duration of pain & $>27$ weeks & $>27$ weeks & 0.485 \\
\hline Pain in the morning [VAS] & $2.7 \pm 2.2$ & $2.5 \pm 1.8$ & 0.465 \\
\hline Daily maximum of pain [VAS] & $5.2 \pm 1.8$ & $4.7 \pm 2.2$ & 0.076 \\
\hline Intake of antibiotics (Ciprobay, Tavanic) & $3 \%$ & $0 \%$ & 0.362 \\
\hline \multicolumn{4}{|l|}{ Previous therapies } \\
\hline Massage & $51 \%$ & $41 \%$ & 0.424 \\
\hline Cross friction & $38 \%$ & $16 \%$ & 0.060 \\
\hline Heat application & $18 \%$ & $22 \%$ & 0.102 \\
\hline Cold application & $44 \%$ & $38 \%$ & 0.371 \\
\hline Shock wave & $15 \%$ & $13 \%$ & 0.111 \\
\hline Eccentric training & $8 \%$ & $0 \%$ & 0.066 \\
\hline Sclerotherapy & $0 \%$ & $3 \%$ & 0.126 \\
\hline Injection of corticosteroids & $56 \%$ & $63 \%$ & 0.475 \\
\hline Injection of Traumeel & $10 \%$ & $0 \%$ & 0.025 \\
\hline Surgical treatment & $3 \%$ & $6 \%$ & 0.311 \\
\hline Bandage & $79 \%$ & $72 \%$ & 0.169 \\
\hline Taping & $10 \%$ & $16 \%$ & 0.176 \\
\hline Kinesiology taping & $10 \%$ & $9 \%$ & 0.050 \\
\hline Collateral tendon diseases & & & 0.369 \\
\hline Pain of the patella tendon & $5 \%$ & $9 \%$ & \\
\hline Pain of the Achilles tendon & $0 \%$ & $6 \%$ & \\
\hline Sulcus ulnaris syndrome & $3 \%$ & $3 \%$ & \\
\hline
\end{tabular}


Table 2 Sports and profession

\begin{tabular}{|c|c|c|c|}
\hline & Group A (Flexibar ${ }^{\circledast}$ ) & Group B (Flexibar ${ }^{\oplus}+\mathrm{XCO}^{\oplus}$ ) & Chi-square test \\
\hline \multicolumn{4}{|l|}{ Sports } \\
\hline Constant sporting activity & $80 \%$ & $91 \%$ & 0.369 \\
\hline Weekly training sessions & $1.6 \pm 0.7$ à $1.7 \pm 1.3 \mathrm{~h}$ & $1.5 \pm 0.6$ à $1.6 \pm 0.7 \mathrm{~h}$ & 0.226 \\
\hline Professional groups & & & 0.271 \\
\hline Employee & $54 \%$ & $56 \%$ & \\
\hline Engineer & $5 \%$ & $13 \%$ & \\
\hline Independent & $3 \%$ & $3 \%$ & \\
\hline Housewife & $5 \%$ & $0 \%$ & \\
\hline Sports teacher/therapist & $0 \%$ & $6 \%$ & \\
\hline Pensioner & $5 \%$ & $0 \%$ & \\
\hline Civil servant & $18 \%$ & $9 \%$ & \\
\hline Craftsman & $5 \%$ & $6 \%$ & \\
\hline Lawyer & $0 \%$ & $6 \%$ & \\
\hline Physician & $3 \%$ & $0 \%$ & \\
\hline \multicolumn{4}{|l|}{ Use of PC } \\
\hline Professional use of PC & $87 \%$ & $91 \%$ & 0.648 \\
\hline Hours of professional use of PC per day & $4.9 \pm 2.6$ & $5.3 \pm 2.7$ & 0.545 \\
\hline Private use of $\mathrm{PC}$ & $92 \%$ & $88 \%$ & 0.768 \\
\hline Hours of private use of PC per day & $0.9 \pm 0.5$ & $1.0 \pm 0.9$ & 0.221 \\
\hline
\end{tabular}

hand and be moved with a powerful movement of the arms to achieve the effect described.

Patients of both groups were asked to keep a diary concerning their pain levels and also training sessions during the whole period of the study.

Before the start of the training phase and after terminating the 12 weeks period, we performed each time an examination, whereby different measurement parameters were collected and the patients had to fill in the DASHScore (score for the disabilities of the arm, shoulder and hand). We measured the strength development according to Jamar, the 2-point discrimination at the distal phalanx of each finger, both radial and ulnar, the vibration sensation (by $128 \mathrm{~Hz}$ tuning fork) on top of the acromion, at the epicondylus humeri radialis and ulnaris, as well as at the distal ending of the radius and the ulna.

\section{Primary goal parameter}

- Course of pain on the visual analogue scale (VAS 010)

\section{Secondary goal parameter}

- DASH-Score (from $0=$ no limitations to $100=$ strong limitations)

- Compliance whilst performing the training period
- Measuring of the strength development according to Jamar $[\mathrm{kg}]$

- Measuring the vibration sensation in $1 / 8$ steps by using a $128 \mathrm{~Hz}$ tuning fork

- Measuring the 2-point discrimination at the distal phalanx of each finger both radial and ulnar

\section{Statistics}

The input and processing of the statistical data was performed with SPSS 17.0. The patients' characteristics were processed using cross tables and chi-square tests. For the analysis of the measured values, we initially calculated averages: average of the 3 attempts of the strength development, average of the 2-point discrmination for each hand, and average of the vibration sensation at the different localisations, etc. We subsequently calculated the changes of the paired $t$ test, comparing before and after. For the comparison between both groups, we used the unpaired $t$ test.

\section{Results}

Randomisation of the patients to 'Group A' (Flexibar') and 'Group B' (Flexibar ${ }^{\circ}+\mathrm{XCO}^{\circ}$ ) resulted in a distribution without relevant differences between the groups. The detailed list of basic characteristics, underlying diseases, diseases of the elbow and collateral tendon diseases can be found in Table 1. The table also shows that the patients in both groups reported symptoms for more 

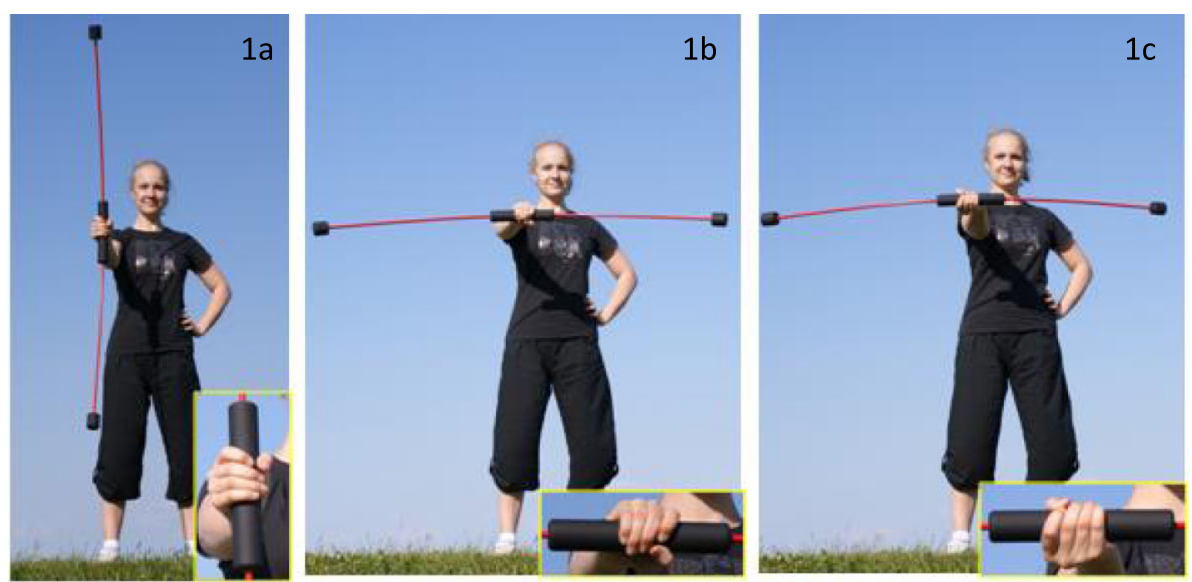

Arm in front of the body. 1a Hand in a neutral position, $\mathbf{1 b}$ Hand in pronation, 1c Hand in supination
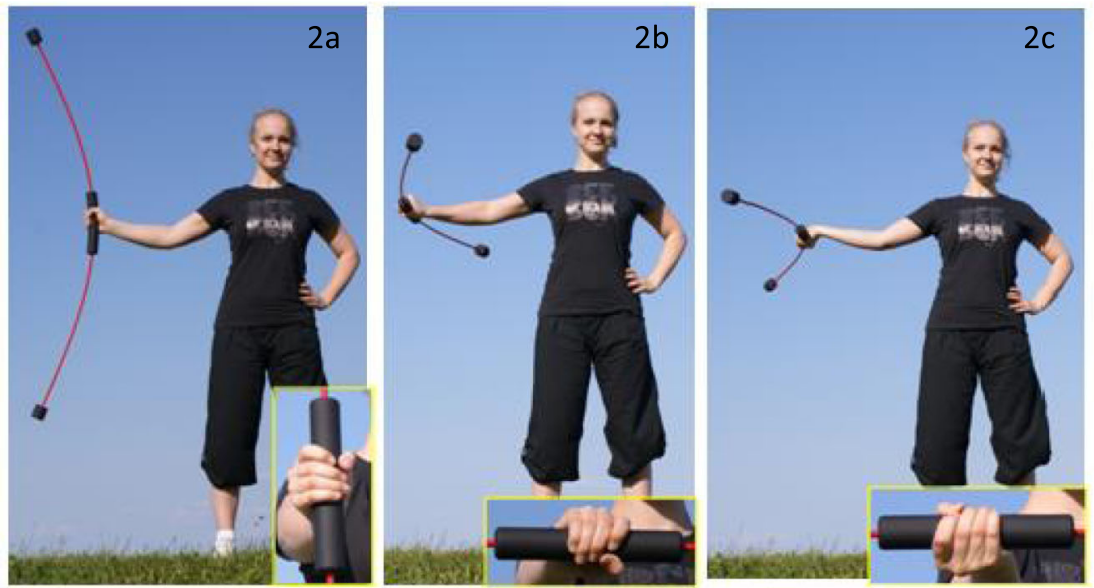

Arm besides the body. $\mathbf{2 a}$ Hand in a neutral position, $\mathbf{2} \mathbf{b}$ Hand in pronation, $\mathbf{2} \mathbf{c}$ Hand in supination
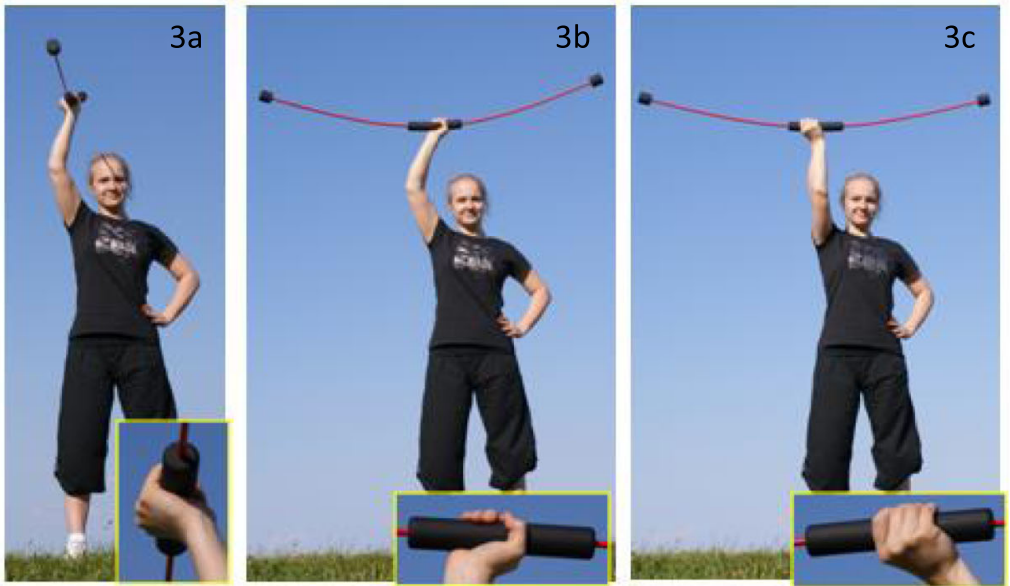

Arm above the head. $\mathbf{3 a}$ Hand in a neutral position, $\mathbf{3 b}$ Hand in pronation, $\mathbf{3 c}$ Hand in supination

Fig. 2 Instructions for the training. Arm in front of the body: 1a Hand in a neutral position, $\mathbf{1 b}$ hand in pronation, 1c hand in supination. Arm besides the body: $\mathbf{2} \mathbf{a}$ Hand in a neutral position, $\mathbf{2} \mathbf{b}$ hand in pronation, $\mathbf{2} \mathbf{c}$ hand in supination. Arm above the head: $\mathbf{3} \mathbf{a}$ Hand in a neutral position, $\mathbf{3} \mathbf{b}$ hand in pronation, $\mathbf{3} \mathbf{c}$ hand in supination 


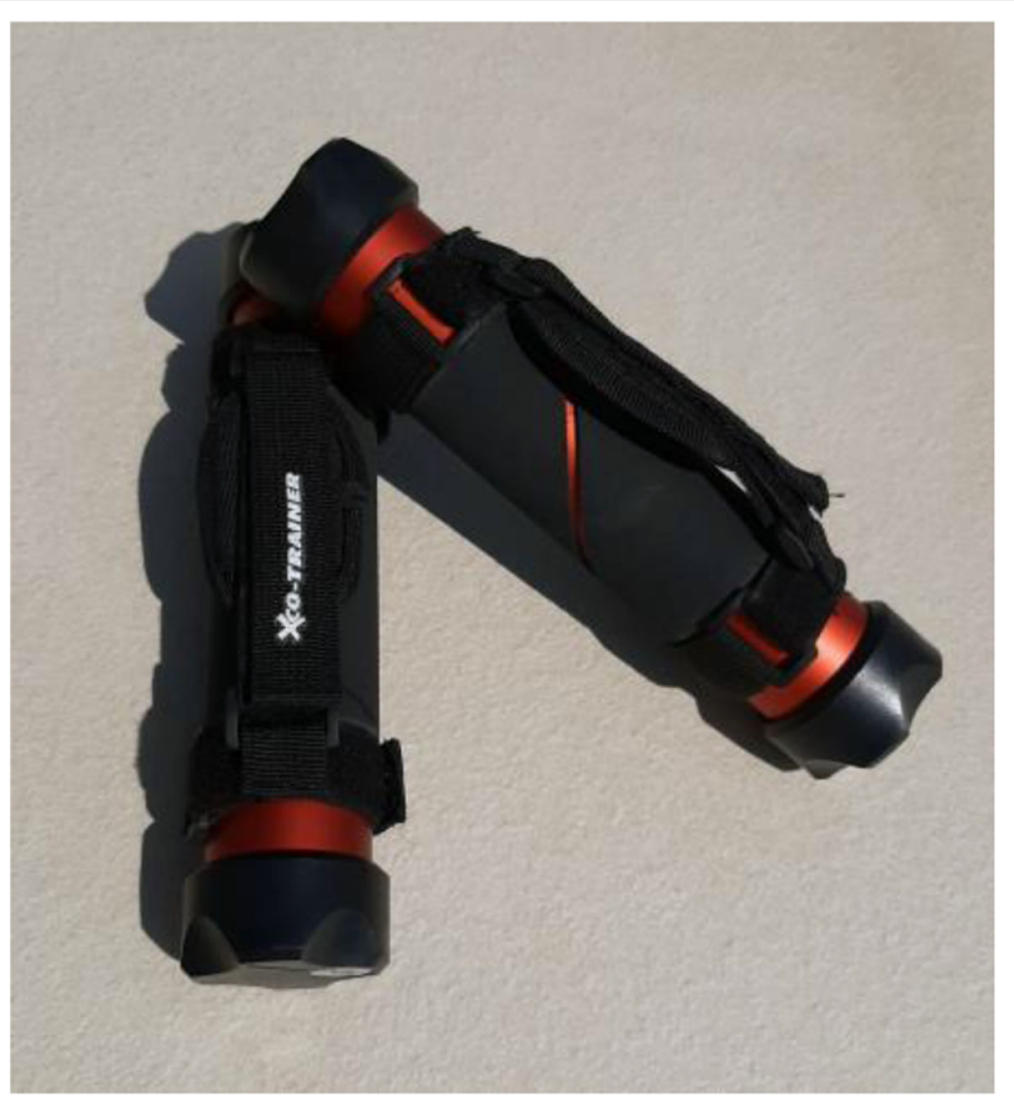

Fig. $3 \times \mathrm{CO}^{\circledast}$ Walking \& Running

than 27 weeks on average when they entered the study. In addition, the treatments already received in advance can also be taken from here. In addition, Table 2 shows the sporting activity, professional activity and PC use.

\section{Primary goal parameter}

\section{Course of pain on the visual analogue scale (VAS 0-10)}

In 'Group A' (Flexibar'), there was a reduction of pain from $3.6 \pm 2.0$ to $2.4 \pm 2.1$, which is corresponding with a decrease of $1.2 \pm 2.5$ points on the pain scale and a $p$ value of $p=0.013$. In 'Group B' (Flexibar ${ }^{\circ}+\mathrm{XCO}^{\circ}$ ), we found a reduction of pain from $3.7 \pm 2.4$ to $2.2 \pm 1.9$ and therefore a decrease of $1.5 \pm 2.4$ points on the pain scale and a $p$ value of $p=0.004$. See also Fig. 4. There was no significant difference between 'Group A' (Flexibar ${ }^{\circ}$ ) and 'Group B' (Flexibar $\left.{ }^{\circ}+\mathrm{XCO}^{\circ}\right)(p=0.899)$.

\section{Secondary goal parameter}

\section{DASH-Score (from $0=$ no limitations to $100=$ strong}

\section{limitations)}

Concerning the DASH-Score, an improvement was achieved from $32 \pm 15$ points before the period of training to $14 \pm 12$ points after the training phase in 'Group $\mathrm{A}^{\prime}$ (Flexibar $\left.{ }^{\circ}\right)$. In 'Group B' (Flexibar $\left.{ }^{\circ}+\mathrm{XCO}^{\circ}\right)$, there was an improvement from $27 \pm 12$ points to $12 \pm 11$ points. This corresponds with an improvement of $44 \%$ in 'Group A' (Flexibar') and $44 \%$ in 'Group B' (Flexibar' $\left.+\mathrm{XCO}^{\circ}\right)$. We were thus able to observe a significant improvement relating to the symptomatic limb with a $p$ value of $p=0.001$ in both groups. This is corresponding with a change for the better of $56 \%$ in both groups (Fig. 5) and without significant difference between the groups $(p=0.677)$.

\section{Compliance whilst performing the training period}

The patients in 'Group A' (Flexibar') trained with the Flexibar $^{\circ}$ on average over a period of $91 \pm 12$ days for $798 \pm 223 \mathrm{~min}$ (corresponding on average to $106 \%$ of the required training), which complies with a weekly training of $61 \pm 17 \mathrm{~min}$ and a daily training of $9 \pm 3$ min. On average, the patients in this group missed $12 \pm$ 11 training sessions (corresponding on average to $15 \%$ of the required training sessions).

The patients in 'Group B' (Flexibar ${ }^{\circ}+\mathrm{XCO}^{\circ}$ ) trained with the Flexibar ${ }^{\circ}$ on average over a period of $95 \pm 17$ days for $825 \pm 192 \mathrm{~min}$ (corresponding on average to $109 \%$ of the required training), which complies with a weekly training of $61 \pm 14 \mathrm{~min}$ and a daily training of 9 $\pm 2 \mathrm{~min}$. On average, the patients in this group missed $10 \pm 10$ training sessions (corresponding on average to 


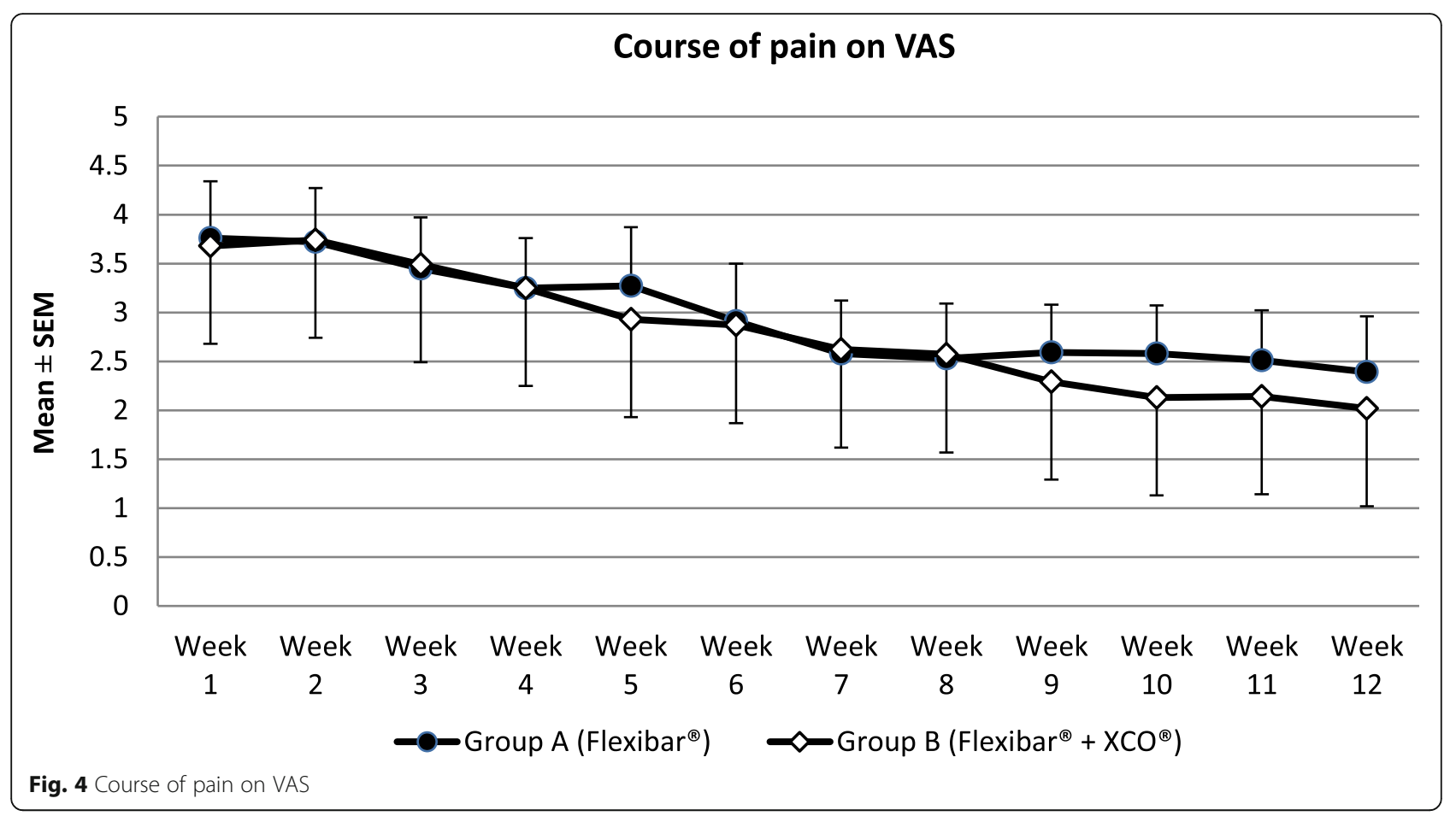

$12 \%$ of the required training sessions). In the same period, they trained with the $\mathrm{XCO}^{\circ}$ on average $648 \pm$ $446 \mathrm{~min}$ (corresponding on average to $135 \%$ of the required practice time), which complies with a weekly training of $47 \pm 27 \mathrm{~min}$ and $27 \pm 12 \mathrm{~min}$ per training session. This practice time was spread on average over 2 \pm 1 training sessions per week. In doing so, the patients in 'Group B' missed $6 \pm 9$ training sessions with the
$\mathrm{XCO}^{\circ}$ (corresponding on average to $25 \%$ of the required training sessions) (Fig. 6).

Measuring of the strength development according to Jamar [kg]

The measurements were taken concerning the symptomatic limb by using the 3-attempt-method, each time with extended as well as with a flexed elbow.

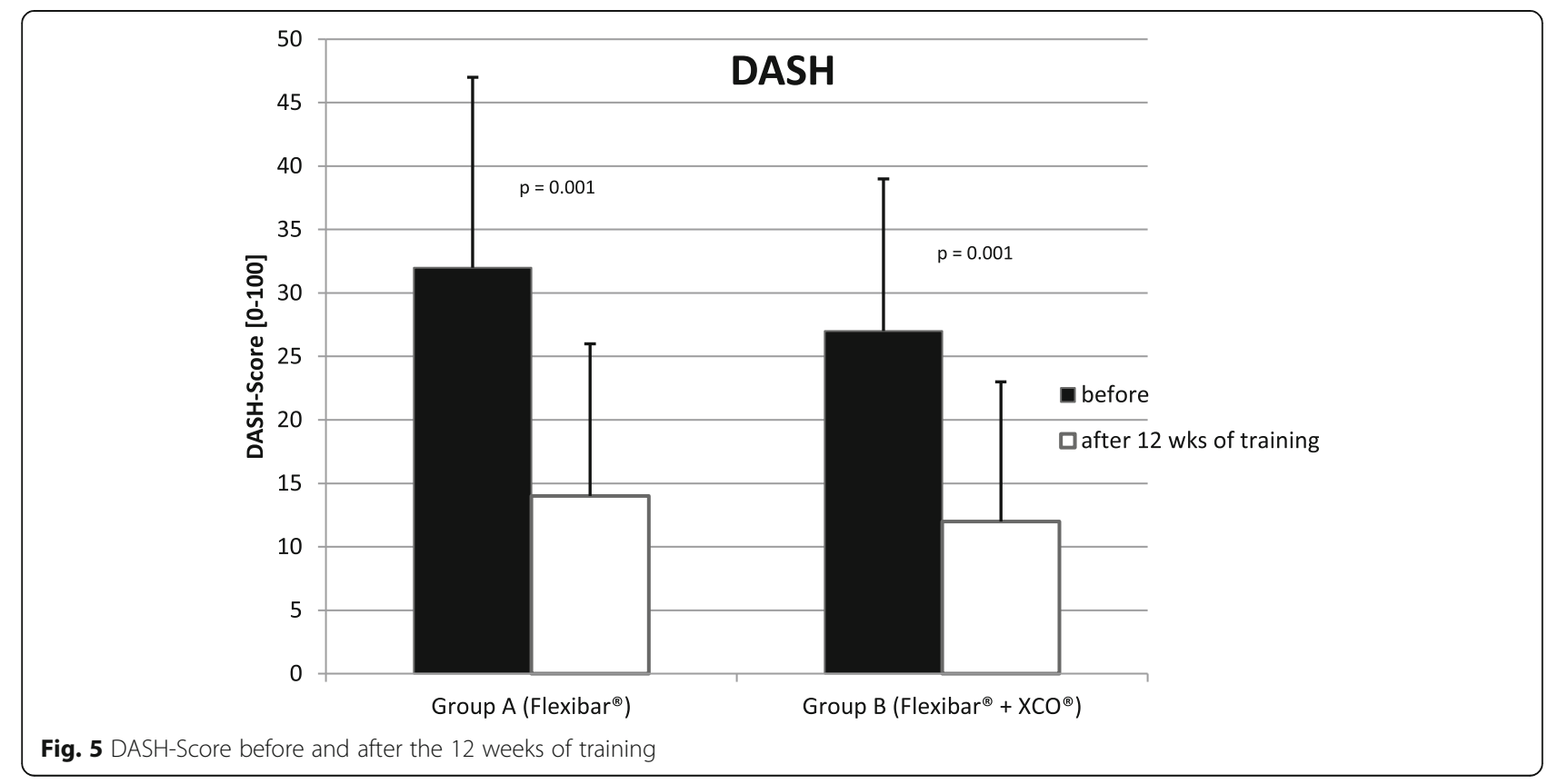




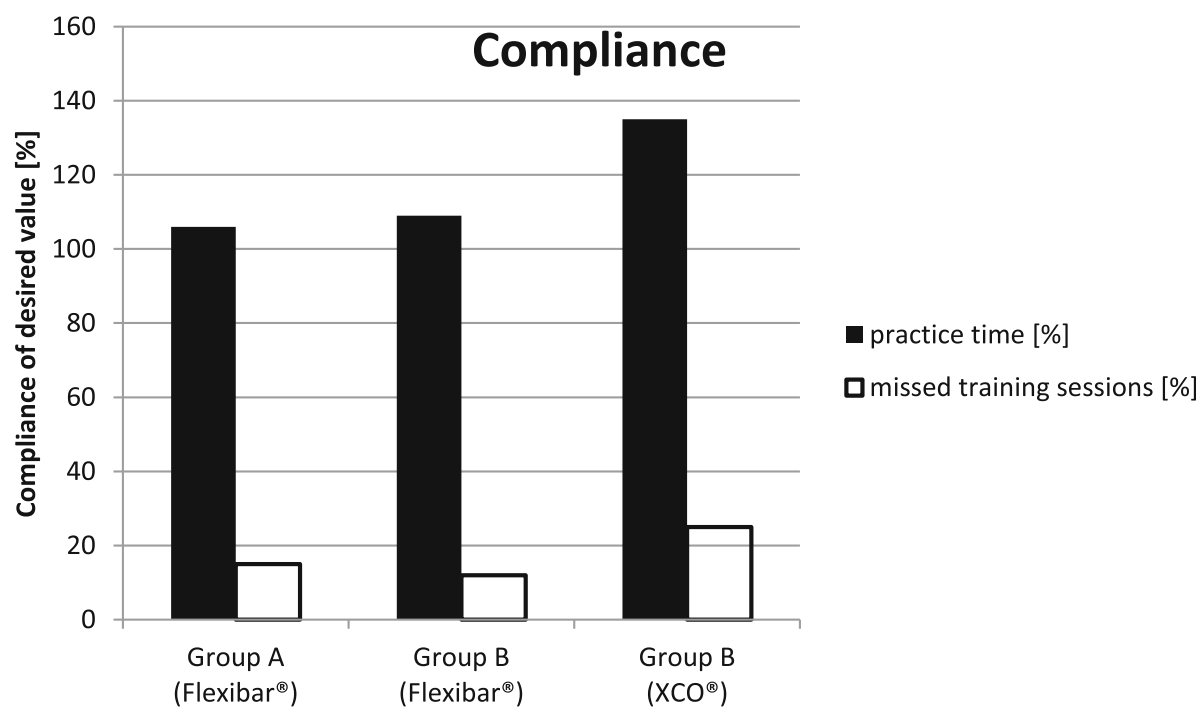

Fig. 6 Synopsis of the compliance of the patients

In 'Group A' (Flexibar'), we found an improvement of the strength development concerning the symptomatic limb when testing with an extended elbow from $24 \pm 12$ $\mathrm{kg}$ to $33 \pm 11 \mathrm{~kg}$ and when testing with a $90^{\circ}$ flexed elbow from $26 \pm 12 \mathrm{~kg}$ to $32 \pm 9 \mathrm{~kg}$. This is corresponding with an increase of the strength development of $38 \%$ (extended) or 23\% (flexed). Therefore, in 'Group A' $\left(\right.$ Flexibar $\left.^{\circ}\right)$, a significant improvement was achieved in both test positions with a $p$ value of $p=0.001$ (extended) and $p=0.004$ (flexed).

In 'Group B' (Flexibar $\left.{ }^{\circ}+\mathrm{XCO}^{\circ}\right)$, we found an improvement of the strength development concerning the symptomatic limb when testing with an extended elbow from $29 \pm 14 \mathrm{~kg}$ to $34 \pm 11 \mathrm{~kg}$ and when testing with a $90^{\circ}$ flexed elbow from $31 \pm 13 \mathrm{~kg}$ to $32 \pm 11 \mathrm{~kg}$. This is corresponding with an increase of the strength development of $17 \%$ (extended) or 3\% (flexed). Therefore, in 'Group B' (Flexibar $\left.{ }^{\circ}+\mathrm{XCO}^{\circ}\right)$, a significant improvement was achieved with a $p$ value of $p=0.005$ when testing with an extended elbow, whilst the testing with a flexed elbow showed only a slight improvement with a $p$ value of $p=0.372$ not (Fig. 7).

Neither the measurement with the elbow extended ( $p$ $=0.735)$ nor the measurement with the elbow flexed $(p$ $=0.677)$ showed significant differences between 'Group $\mathrm{A}^{\prime}$ (Flexibar $\left.{ }^{\circ}\right)$ and 'Group B' (Flexibar ${ }^{\circ}+\mathrm{XCO}^{\circ}$ ).

\section{Measuring the vibration sensation in $1 / 8$ steps by using $a$ $128 \mathrm{~Hz}$ tuning fork}

In 'Group A' (Flexibar ${ }^{\circ}$ ), we could find an improvement of the vibration sensation for the symptomatic limbs on average from $6.3 / 8 \pm 0.6 / 8$ to $6.5 / 8 \pm 0.5 / 8$ and therefore

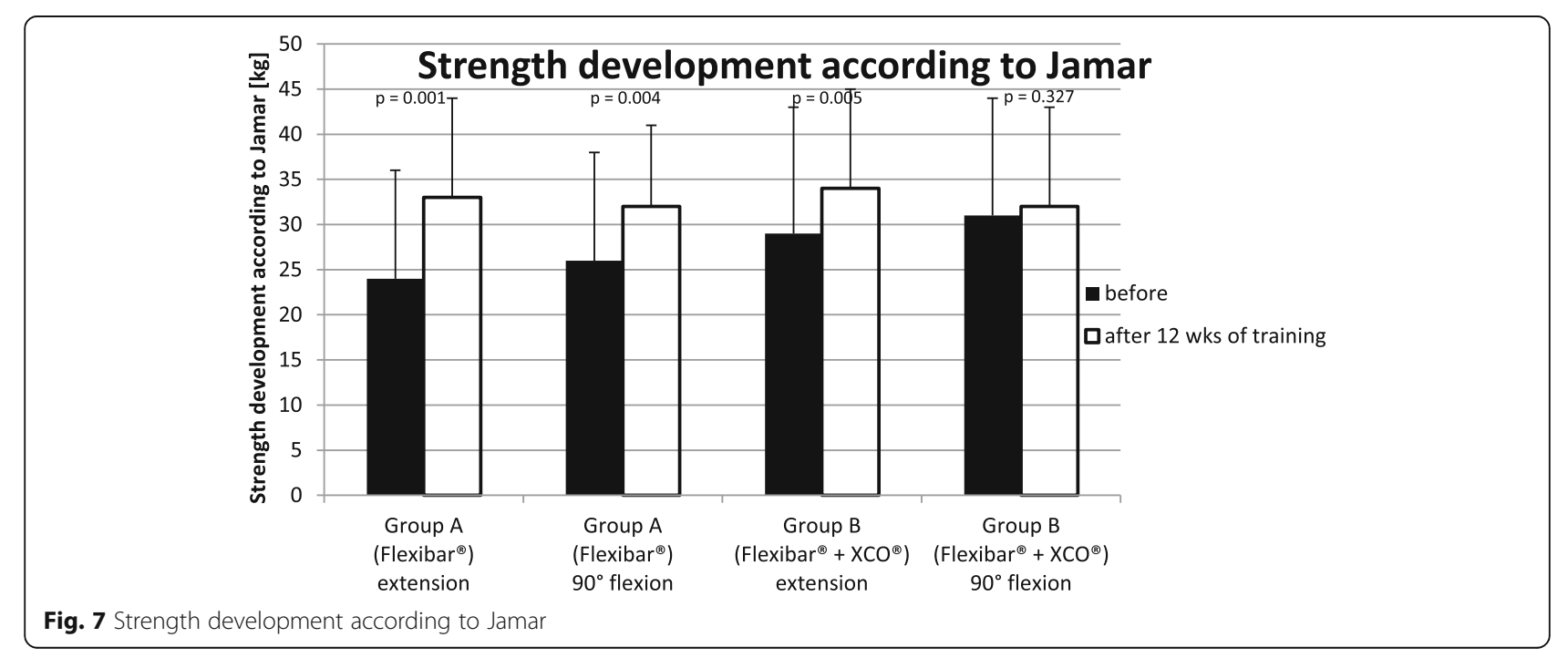


about 3\%. In 'Group B' (Flexibar ${ }^{\circ}+\mathrm{XCO}^{\circ}$ ), we could find an improvement for the symptomatic limbs on average from $6.3 / 8 \pm 0.7 / 8$ to $6.6 / 8 \pm 0.5 / 8$ and therefore about $5 \%$. In both groups, a significant improvement of the vibration sensation was achieved with a $p$ value of $p$ $=0.001$ in 'Group A' (Flexibar') and $p=0.003$ in 'Group $\mathrm{B}^{\prime}\left(\right.$ Flexibar $^{\circ}+\mathrm{XCO}^{\circ}$ ) (Fig. 8), but without significant difference between the groups $(p=0.091)$.

\section{Measuring the 2-point discrimination at the distal phalanx of each finger both radial and ulnar}

In 'Group A' (Flexibar ${ }^{\circ}$ ), we could find an improvement of the 2-point discrimination for the symptomatic limbs on average from $5.2 \mathrm{~mm} \pm 0.7 \mathrm{~mm}$ to $4.3 \mathrm{~mm} \pm 0.6 \mathrm{~mm}$ and therefore about $18 \%$. In 'Group B' (Flexibar ${ }^{\circ}+$ $\mathrm{XCO}^{\circ}$ ), we could find an improvement of the 2-point discrimination for the symptomatic limbs on average from $5.0 \mathrm{~mm} \pm 0.7 \mathrm{~mm}$ to $4.4 \mathrm{~mm} \pm 0.6 \mathrm{~mm}$ and therefore about $12 \%$. In conclusion, in both groups, we measured a significant improvement of the 2-point discrimination with a $p$ value of $p=0.001$ (Fig. 9), but there was no significant difference between the groups $(p=0.959)$.

\section{Discussion and conclusions}

The primary purpose of any therapeutic effort for treating patients with lateral epicondylitis is the reduction of subjectively experienced pain by the patient which we put in the focus of our study as our primary goal parameter. In doing so, we were able to notice a continuous decline of the experienced pain intensity over the whole period of the study (see Fig. 4), so that both groups lastly achieved a significant reduction of the pain $(34 \%$ in 'Group A' (Flexibar') and 40\% in 'Group B' (Flexibar ${ }^{\circ}+$
$\left.\mathrm{XCO}^{\circ}\right)$ ). However, we could not determine a significant difference between both groups, so that we have to conclude that a more intensive training with different devices does not bring any additional benefit for the development of pain. In addition, we could verify a significant improvement of functionality of the upper limb in both groups, which we established by the DASHScore (see Fig. 5). In both groups, a reduction of the point value was recorded by $56 \%$, which corresponds to an even more remarkable improvement than the pain reduction. We could not find a significant difference between the both practice groups here either. As both parameters (VAS and DASH) are certainly mostly relevant for the contentment of the patients but despite everything have to be regarded as subjective parameters, we have added objectively measurable parameters to our analysis-the strength development, the vibration sensation and the 2-point discrimination. With regard to the measurement of strength development, it is hardly possible to objectively test the muscles that are primarily stressed by the training, so we used the grip strength according to Jamar as a measurable parameter. Since the muscles tested here are also stressed to a certain extent (firm grip of the equipment during the exercise), but are not the actual target muscle group of the treatment, another explanation for the improvement in the values could be assumed as follows: The most likely explanation is pain reduction and the thus facilitated exercise performance. In particular, we were able to observe significant improvements when performing the exercise with the elbow extended-which corresponds to the position that was initially already more painful. These values can therefore be interpreted as an improvement in functionality or discomfort rather than a pure increase in

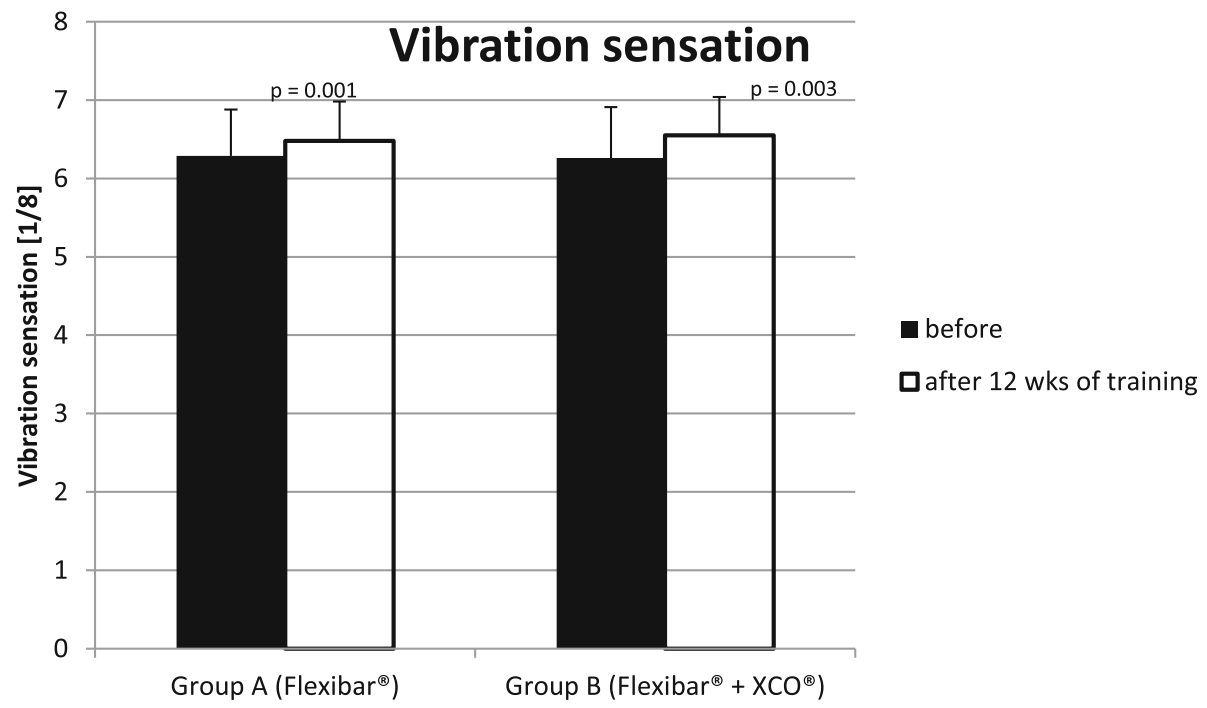

Fig. 8 Development of the vibration sensation 


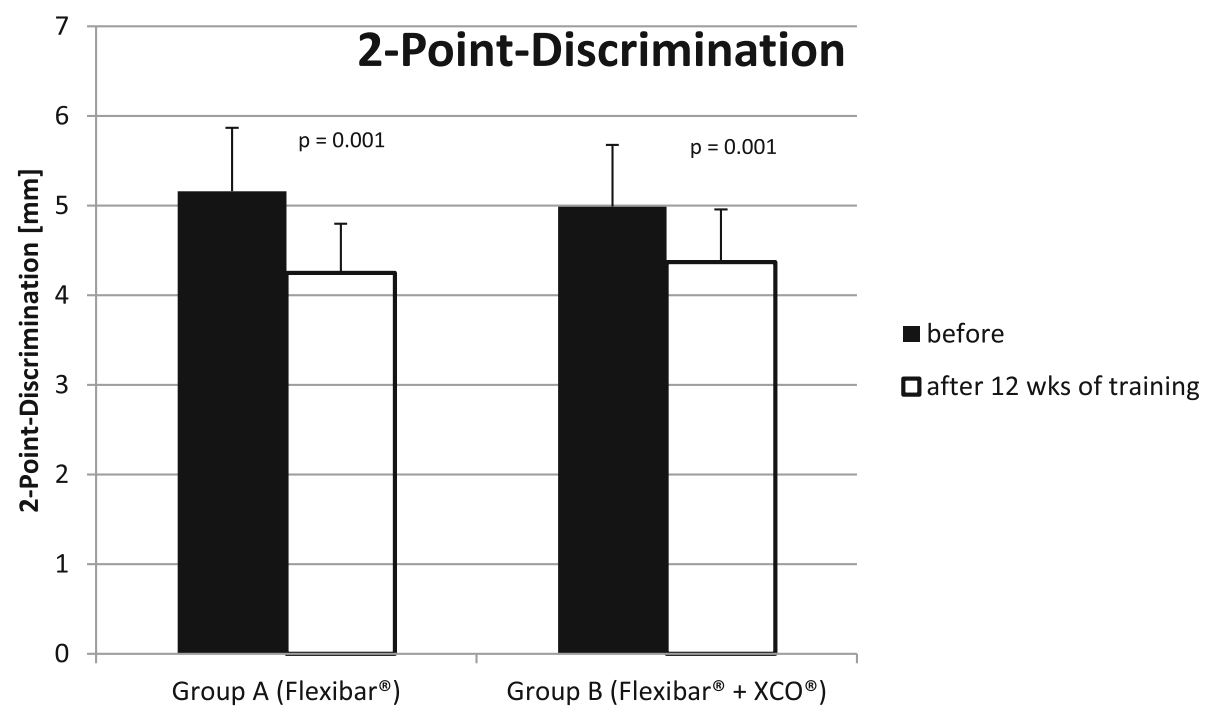

Fig. 9 Development of the 2-point discrimination

strength. In 'Group A' (Flexibar'), we found a significant improvement in both testings with the elbow extended and with the elbow flexed, whilst in 'Group B' (Flexibar' $+\mathrm{XCO}^{\circ}$ ), only the testing with the elbow extended showed a significant improvement and the testing with the elbow flexed only showed a slight improvement. The fact that 'Group A' (Flexibar ${ }^{\circ}$ )-with the less intensive training-showed a better result here indicates that grip strength is not essential for the development of the first two goal parameters and that an increase in strength corresponding to the training intensity at least does not affect the tested muscle group. Furthermore, we also wanted to directly objectify the intended and expected effect on proprioceptive capabilities. For this purpose, we decided to test vibration sensation and 2-point discrimination in order to obtain measurable and comparable values. Again, we could prove a statistically significant improvement in both groups, both for the vibration sensation and also for the 2-point discrimination as an indication that the intervention was able to achieve the intended effect on the proprioception capability. Also here, a more intensive proprioceptive training with two different devices did not result in a bigger improvement of the proprioceptive capabilities. It should not be overlooked that this therapeutic option is bound to a sufficient compliance of the patients. Within our study, we asked the patients to keep a training diary that gave us the chance to evaluate the compliance. We could find that the training with the Flexibar ${ }^{\circ}$ was rarely missed and sometimes even done more than required, whilst about $25 \%$ of the training sessions with the $\mathrm{XCO}^{\circ}$ were missed. This is probably due to the fact that the flexibar exercises are easier to integrate into the daily routine of a working patient than jogging or walking exercises. The compliance as a very important factor of the success of this therapeutic options is also for certain one of the most relevant limitations. As a lot of patients hope for an immediate relief of their symptoms without any active support by themselves, a reduced compliance-beyond the setting of a clinical trial with a voluntary participation-is possible, whereby the therapeutic success could ultimately be reduced. Another limitation could be the correct execution of the exercise performance which is difficult to be controlled during autonomous training. Within the study, we gave exact exercise instructions to our patients at the beginning of the training period and also checked the exercise performance probatory at the beginning as well as at the end of the training period. Only 1-2 patients of each group showed an incorrect exercise performance, but we could also detect significant differences in the intensity of the execution; the influence of which on the outcome could not be measured. These differences may be attributed to the great heterogeneity of the collective of probands, but should also be seen in the public patient collective. Whether the collected results we have obtained can also be transferred to similar training devices of other manufacturers cannot be said with certainty, since we have not carried out a comparative study.

Overall, we were able to prove that the performance of a proprioceptive and ballistic training with the Flexibar ${ }^{\circ}$ resulted in significant improvement of the subjectively experienced symptoms of the patients. However, a further benefit could not be shown by an additional training with the $\mathrm{XCO}^{\circ}$. Furthermore, we were able to measure other improvements with objective measurement parameters-in this case, the strength development, the vibration sensation and the 2-point 
discrimination-which demonstrated the effectiveness of this training.

Within comparative research in online databases, a large number of hits are found in search of clinical training studies for patients with lateral epicondylitis. Peterson et al. [14] demonstrated, for example, that an active training in patients with lateral epicondylitis can cause a more rapid relief of pain than a purely wait-and-see behaviour. In another clinical trial, Viswas et al. [15] found a superiority of a controlled exercise programme compared with a treatment with Cyriax physiotherapy. In addition, studies comparing a stretching with a consistent use of an orthosis [16] demonstrated an advantage of the active to the passive intervention. Various studies addressed the effect of an eccentric training of patients with lateral epicondylitis. At this, Söderberg et al. [17] could prove a significantly higher increase of a pain-free hand grip by combining an eccentric training with the use of an orthosis than the control group which received only the orthosis. Peterson et al. [18] finally compared two active training methods-eccentric versus concentric training-and found an advantage of the eccentric training over the concentric training for patients with lateral epicondylitis. However, all of the abovementioned studies have in common that no attention was paid to the reduced proprioception capability in the area of the elbow, which has been proven by Juul-Kristensen et al. [5]. However, examinations of other joints have already shown that proprioceptive training can have a positive effect on the functionality and reduction of symptoms in diseased joints. For comparison, other studies can be used which also detected a reduced proprioceptive capability in patients with symptomatic gonarthrosis [19]. Further studies demonstrated the effectiveness of proprioceptive training compared with a control group [20] and other results even show an advantage of a proprioceptive training compared with an isometric training [21]. Concerning the beneficial effects of a proprioceptive training for patients with lateral epicondylitis, only a few studies have been carried out yet. However, Tripp et al. [22] demonstrated in their study an improvement of the proprioceptive capabilities in the area of the elbow by performing a vibration training using vibrating dumbbells and varying frequencies. This trial used a collective of probands without a symptomativ lateral epicondylitis though. In the course of our study, we were able to prove that patients with lateral epicondylitis, which are more likely to have proprioceptive deficits as shown in other trials [5], active vibration training could cause an improvement of the proprioception itself as well as an improvement of grip strength, functionality and in particular pain reduction. In this setting, evaluated training devices can be used by the patients in the home environment, so that an independent training is possible without a commitment to a location or a fixed date and therefore the integration into the daily work routine of the primarily concerned working patient population is possible without difficulties.

One limitation of the study is that it was not possible to recruit a sufficient number of probands suffering permanent symptoms if there had been the chance that they could have been randomised to a group without treatment. Thus, a comparative assessment with the spontaneous outcome in our collective is not possible. Furthermore, we cannot make any statement about devices from other manufacturers, because we did not test them and it is not certain whether the results could be transferred in this way.

\section{Abbreviations}

DASH-Score: Score for the disabilities of the arm, shoulder and hand; VAS: Visual analogue scale

\section{Acknowledgements \\ Not applicable.}

\section{Authors' contributions}

The study design was worked out by Berit Schiffke-Juhasz and Prof. Dr. med. K. Knobloch together. The clinical investigations and data collection were conducted by Berit Schiffke-Juhasz. Subsequently, the data set was analysed with the support of the statistician Dr. rer. nat. habil. L. Hoy and the results were interpreted by Berit Schiffke-Juhasz and Prof. Dr. med. K. Knobloch. The preparation of the article, as well as the graphics and tables, was done by Berit Schiffke-Juhasz and the contents were again coordinated with Prof. Dr. med. K. Knobloch. Prof. Dr. med. P. M. Vogt, as head of the department, was responsible for supervising the study. The authors read and approved the final manuscript.

Funding

No other funding agency was involved anymore.

\section{Availability of data and materials}

The datasets generated and analysed during the current study are not publicly available due still contain data that have not yet been analysed but are available from the corresponding author on reasonable request.

\section{Declarations}

\section{Ethics approval and consent to participate}

We have the agreement of the ethics committee from Medizinische Hochschule Hannover, Germany.

\section{Consent for publication}

No personal data is disclosed in our article. The photos used in Fig. 2 show the main author herself and may be published.

\section{Competing interests}

For our study, we received the training devices for our patients from FlexiSports $^{\circledast}$ and the training devices remained in the property of the patients after the study. Apart from that, we received no further grants or support from Flexi-Sports ${ }^{\oplus}$ or another company or institution. Conversely, FlexiSports $^{\circledast}$ has not demanded the results of our trial to publish them for advertising. So, we can declare that there is no conflict of interest for us.

\section{Author details}

${ }^{1}$ Herzogin Elisabeth Hospital, Braunschweig, Germany. ${ }^{2}$ Sportpraxis Knobloch, Hannover, Germany. ${ }^{4}$ Medizinische Hochschule Hannover, Hannover, Germany. ${ }^{3}$ Formerly Medizinische Hochschule Hannover, Hannover, Germany. 
Received: 30 March 2021 Accepted: 4 July 2021

Published online: 27 July 2021

\section{References}

1. Stöckle U. Ellenbogenchirurgie. Standardverfahren, Tipps und Tricks. 1. Auflage; 2010.

2. Verhaar JA. Tennis elbow. Anatomical, epidemiological and therapeutic aspects. Int Orthop. 1994;18(5):263-7. https://doi.org/10.1007/BF00180221.

3. Haahr JP, Andersen JH. Physical and psychosocial risk factors for lateral epicondylitis: a population based care-referent study. Occup Environ Med. 2003:60(5):322-9. https://doi.org/10.1136/oem.60.5.322

4. Shiri R, Viikari-Juntura $E$, Varonen $H$, Heliövaara M. Prevalence and determinants of lateral and medial epicondylitis: a population study. Am J Epidemiol. 2006;164(11):1065-75. https://doi.org/10.1093/aje/kwj325.

5. Juul-Kristensen $B$, Lund $H$, Hansen $K$, Christensen $H$, Denneskiold-Samsøe B, Bliddal H. Poorer elbow proprioception in patients with lateral epicondylitis than healthy controls: a cross-sectional study. J Shoulder Elbow Surg. 2008;17(1 Suppl):72S-81S.

6. Sevie TL, Wilson JK. Treating lateral epicondylitis. Sports Med. 1999;28(5): 375-80. https://doi.org/10.2165/00007256-199928050-00006.

7. Van De Streek MD, Van Der Schans CP, De Greef MH, Postema K. The effect of a forearm/hand splint compared with an elbow band as a treatment for lateral epicondylitis. Prosthet Orthot Int. 2004;28(2):183-9. https://doi.org/1 0.1080/03093640408726703.

8. Garg R, Adamson GJ, Dawson PA, Shankwiler JA, Pink MM. A prospective randomized study comparing a forearm strap brace versus a wrist splint fort he treatment of lateral epicondylitis. J Shoulder Elbow Surg. 2010;19(4):50812. https://doi.org/10.1016/j.jse.2009.12.015.

9. Nichols AW. Complications associated with the use of corticosteroids in the treatment of athletic injuries. Clin J Sport Med. 2005;15(5):370-5.

10. Bisset L, Beller E, Jull G, Brooks P, Darnell R, Vincenzino B. Mobilisation with movement and exercise, corticosteroid injection, or wait and see for tennis elbow: randomised trial. BMJ. 2006;333(7575):939. https://doi.org/10.1136/ bmj.38961.584653.AE.

11. Li A, Wang H, Yu Z, Zhang G, Feng S, Liu L, et al. Platelet-rich plasma vs. corticosteroids for elbow epicondylitis: a systematic review and metaanalysis. Medicine (Baltimore). 2019;98(51):e18358.

12. Ruiz AG, Diaz GV, Fernández BR, Ruiz De Vargas CE. Effects of ultrasoundguided administration of botulinum toxin (incobotulinumtoxin A) in patients with lateral epicondylitis. Toxins (Basel). 2019;11(1):46. https://doi. org/10.3390/toxins11010046.

13. Newcomer KL, Laskowski ER, Idank DM, McLean TJ, Egan KS. Corticosteroid injection in early treatment of lateral epicondylitis. Clin J Sport Med. 2001; 11(4):214-22. https://doi.org/10.1097/00042752-200110000-00002.

14. Peterson M, Butler S, Eriksson M, Svärdsudd K. A randomized controlled trial of exercise versus wait-list in chronic tennis elbow (lateral epicondylosis). Ups J Med Sci. 2011;116(4):269-79. https://doi.org/10.3109/03009734.2011.600476.

15. Viswas R, Ramachandran R, Korde AP. Comparison of effectiveness of supervised exercise program and Cyriax physiotherapy in patients with tennis elbow (lateral epicondylitis): a randomized clinical trial. ScientificWorldJournal. 2012;2012:939645.

16. Sölveborn SA. Radial epicondylalgia ('tennis elbow'): treatment with stretching or forearm band. A prospective study with long-term follow-up including range-of-motion measurements. Scand J Med Sci Sports. 1997;7(4):229-37.

17. Söderberg J, Grooten WJ, Ang BO. Effects of eccentric training on hand strength in subjects with lateral epicondylalgia: a randomized-controlled trial. Scand J Med Sci Sports. 2012;22(6):797-803. https://doi.org/10.1111/j.1 600-0838.2011.01317.x

18. Peterson M, Butler S, Eriksson M, Svärdsudd K. A randomized controlled trial of eccentric vs. concentric graded exercise in chronic tennis elbow (lateral elbow tendinopathy). Clin Rehabil. 2014;28(9):862-72. https://doi.org/10.11 77/0269215514527595

19. Chen Y, Yu Y, He CQ. Correlations between joint proprioception, muscle strength, and functional ability in patients with knee osteoarthritis. Sichuan Da Xue Xue Bao Yi Xue Ban. 2015:46(6):880-4.

20. Tabacs J, Krowchuk NM, Garland SJ, Carpenter MG, Hunt MA. Dynamic balance training improwes physical function in individuals with knee osteoarthritis: a pilot randomized controlled trial. Arch Phys Med Rehabil. 2017;98:1586.

21. Ojoawo AO, Olaogun MO, Hassan MA. Comparitive effects of proprioceptive and isometric exercises on pain intensity and difficulty in patients with knee osteoarthritis: a randomized control study. Technol Health Care. 2016;24(6) 853-63. https://doi.org/10.3233/THC-161234.
22. Tripp BL, Faust D, Jacobs P. Elbow joint position sense after neuromuscular training with handheld vibration. J Athl Train. 2009;44(6):617-23*9.

\section{Publisher's Note}

Springer Nature remains neutral with regard to jurisdictional claims in published maps and institutional affiliations.
Ready to submit your research? Choose BMC and benefit from:

- fast, convenient online submission

- thorough peer review by experienced researchers in your field

- rapid publication on acceptance

- support for research data, including large and complex data types

- gold Open Access which fosters wider collaboration and increased citations

- maximum visibility for your research: over $100 \mathrm{M}$ website views per year

At $\mathrm{BMC}$, research is always in progress.

Learn more biomedcentral.com/submissions 